\title{
Impact of the Tip Vortex on the Passage Flow Structures of a Jet Fan with Symmetric Blades
}

\section{Fernández Oro, J.M; Argüelles Díaz, K.M; Santolaria Morros, C. and Ballesteros-}

Tajadura, $\mathbf{R}$.

Universidad de Oviedo, Área de Mecánica de Fluidos.

Campus de Viesques, 33271, Gijón (Asturias), Spain.

jesusfo@uniovi.es

Abstract: The goal of the study is the simulation of the flow inside a rotor with elliptic airfoils, where the Kutta condition cannot be satisfied. This work develops a threedimensional numerical modeling of a monoplane axial jet fan with symmetric blades. The 3D model includes tip clearance gridding and turbulence modeling based on high-order RANS schemes. The flow patterns inside the blade passage and the wake-core structure will be studied at design operating conditions. Also, the interaction of the tip leakage flow with blade-to-blade structures will be analyzed in detail. The investigation shows how the tip leakage vortex modifies the blade loading on the suction surface. The leakage flow rolls-up in a vortical structure at the suction side, establishing a mixing mechanism that produces a low axial velocity region. As a result, the adverse pressure gradient is enhanced and a major flow separation overcomes. This feature is especially critical in case of a rotor with symmetric blades, where the flow is always detached at the trailing edge. The simulation is carried out using a commercial code, FLUENT, which resolves the Navier-Stokes set of equations. A high dense mesh is introduced in the model, so tip 
leakage is expected to be well-captured. Different turbulence models have been tested in order to determine the most accurate choice. It is shown that a linear Reynolds Stress Model (RSM) provides velocity distributions more adjusted to experimental data. This suitable prediction for rotating flow passages is a consequence of the characteristics of the model: consideration of anisotropic turbulence and direct inclusion of curvature and rotation effects in the transport equations. Therefore, swirl effects of the tip vortex can be modeled correctly. The numerical results are compared with previous experimental data of velocity fields to validate the simulation. In particular, the instantaneous wake flow structure was measured with a two hot-wire anemometer. Axial and tangential velocity profiles were obtained after pitch-averaging the time-resolved flow patterns.

Keywords: Jet fan, leakage flow, tip vortex, tip clearance, 3D simulation, symmetric blades, tunnel ventilation, longitudinal ventilation system.

\section{NOTATION}

\begin{tabular}{|c|c|c|}
\hline$\Omega[\mathrm{rad} / \mathrm{s}]$ & $=$ & Rotational speed \\
\hline$C_{p}[-]$ & $=$ & Pressure coefficient : $\left(p-p_{\text {inlet }}\right) / 0.5 \rho W^{2}$ \\
\hline$\zeta_{L}$ & $=$ & Total pressure loss coefficient: $\left(p_{o}-\left(p_{0}\right)_{\text {inlet }}\right) / 0.5 \rho U^{2}$ \\
\hline$H^{\prime}[-]$ & $=$ & Non-dimensional helicity \\
\hline$H_{12}[-]$ & $=$ & Shape factor \\
\hline$h$ & $=$ & Blade span \\
\hline$s$ & $=$ & Streamwise coordinate \\
\hline$c$ & $=$ & Chord \\
\hline$\stackrel{1}{v}$ & $=$ & Velocity vector \\
\hline$R e$ & $=$ & Reynolds number \\
\hline$W$ & $=$ & Relative velocity \\
\hline$\phi$ & $=$ & Flow coefficient : $\left(U / U_{\text {tip }}\right)$ \\
\hline$\delta_{1}$ & $=$ & Displacement thickness \\
\hline$\delta_{2}$ & $=$ & Momentum thickness \\
\hline$\eta$ & $=$ & Hydraulic efficiency \\
\hline$\Delta P$ & $=$ & Total-to-total pressure rise \\
\hline$U_{a x}$ & $=$ & Axial velocity \\
\hline$U_{\theta}$ & $=$ & Tangential velocity \\
\hline (tip) & $=$ & Tip \\
\hline$T E$ & $=$ & Trailing edge \\
\hline
\end{tabular}




$\begin{array}{cll}L E & = & \text { Leading edge } \\ P S & = & \text { Pressure side } \\ S S & = & \text { Suction side } \\ - & = & \text { Mean value }\end{array}$

\section{INTRODUCTION}

Axial jet fans are commonly used for longitudinal ventilation systems inside road tunnels (figure 1). They impart a high velocity jet to some of the air in the tunnel which then gradually mixes with remaining air moving it along the tunnel length. Normally, banks of fans are installed at intervals to produce an effective airflow from one end of the tunnel to the other. The jet fans are cantilevered from the ceiling of the tunnel using supporting devices. In front of each side of the impeller there is an aerodynamically designed, nonrotating nose fairing. The fan impeller is mounted directly on the electric motor shaft, which is isolated from the air stream with the nose fairing and a cylindrical casing.

The reduced manufacturing costs and their low requirements make them particularly suitable for that kind of applications. Mostly, jet fans are designed for just one flow sense, which matches with the traffic direction when the tunnel is unidirectional. But when the traffic is bidirectional, the jet fan must be reversible, with equal airflow and thrust in each direction. So it is necessary to use symmetric uncambered blades for the fan impeller. In addition, not only bidirectional road tunnels require reversible jet fans. In case of fire inside a highway tunnel, depending on the fire location or the tunnel slope, it could be necessary to blow in the nominal mode or in the reverse one. Hence, this operational requirement makes impossible the inclusion of stator or guide vanes, so simplified monoplane designs based on elliptical uncambered blades are introduced.

Therefore, the typical characteristic of a reversible jet fan is the particular geometry of the rotor spanwise sections. Thus, if symmetry must be satisfied, then the blade profile 
must be uncambered (figure 2). This design gives similar efficiency for reverse and nominal operating modes, but overall flow conditions are poor. Without camber, lifting coefficients are very low, incidence is high and the airfoils work near stall conditions (boundary layer completely detached at the trailing edge). Although a reversible jet fan is just designed for one unique operating point, there is always flow separation on the suction side.

This investigation deals with the impact of the tip leakage flow on the shear layers of the wake shed by elliptic blades in a symmetric bladed jet fan. At the present time, little research work has been done in elliptic profile performance on an axial jet fan [1-2]. In particular, few data about losses are found when these airfoils are used for turbomachinery. Basically, this is because uncambered blades are not used for compressors: since high pressure ratios are needed, the rotor is designed to operate with large blade loadings, so important blade curvatures are mandatory. Also, they require reduced airfoil losses in order to increase the overall efficiency. Therefore, symmetric profiles are not suitable for compressors, due to the poor aerodynamic features discussed above. Their use is limited to jet fans, which are designed to provide only dynamic pressure with an atmospheric jet expansion. To the authors' knowledge, there have been no investigations of the tip clearance and its influence on the steady performance of any symmetric axial jet fan. Most researchers on this topic have been interested on high-speed compressors for gas turbines. Typically, these compressors are designed to present a very small tip gap to control the tip leakage, extremely driven by the high pressure differences between the suction and pressure sides of the blades. Conversely, though axial jet fans do not present high pressure differences, they are usually mounted with large tip clearances to facilitate the mechanical assembly, reinforcing the impact of the tip leakage on the performance. 
Main research of tip leakage flow in compressors has pointed out that the tip region flow has a major influence on stability and stall conditions [3]. Much effort has been focused on the understanding of the vortical dynamics associated to the tip leakage flow. Different theoretical models have been proposed to explain the roll-up mechanism of the tip vortex [4]; while others described the leakage flow as a jet driven by pressure differences across the blade tip [5-6]. The vortical structure of the tip leakage flow has been observed in both linear cascades [7] and axial flow compressors, using hot-wire and five-hole probes [8-9]. These techniques are intrusive, especially when the probes are introduced in the tip clearance [10], but provide valuable information of the velocity field. LDV systems have been also employed to measure the three-dimensional velocity field in the tip region of two-stage axial compressors [11]. Tip clearance flow is also a source of aerodynamic noise. Several publications show that the periodic velocity fluctuation in the tip clearance generates discrete frequency noise, while mixing with passage-averaged velocity patterns produces broadband noise [12]. In addition, noise is increased at low flow rate as a direct consequence of the interaction between tip leakage vortex and the adjacent pressure surface of the blade [13]. A reduction in the mass flow rate implies a major interaction of near stall conditions on the blade surfaces with tip clearance flow structures resulting in higher noise sources and flow blockage [14]. Recently, CFD techniques have been also introduced as a powerful tool to characterize the impact of tip leakage structures onto the passage-averaged flow. Some strategies assume that there is flow periodicity across a non-gridded region above the blade tip, while others consists in fully gridding the gap with a separate grid block [15-16]. In case of gridding the gap, the model requires intensive computational resources due to the near-wall grid spacing recommended for the tip gap. It has been demonstrated that such a grid distribution has a significant impact on accurate prediction of the clearance flow [16]. 
In the present study, detailed analysis of the flow structure of a jet fan with symmetric blades will show the effect of the tip clearance flow on the detached boundary layer over the trailing edges of the blades, even at the design operating point. A major loss source due to the mixing of tip vortex with flow separation at the blade suction surface will be presented through a 3D numerical modeling of the jet fan with tip clearance gridding. As there are no outlet guide vanes, the mixing of the tip vortex structure with the main flow is fully highlighted. The numerical modelling will be validated through previous measurements of ensemble-averaged and phase-locked representations of the flow downstream of the rotor.

\section{AXIAL JET FAN AND OPERATING PARAMETERS}

Axial jet fans are designed to provide a considerable airflow inside the tunnel, induced by a high momentum transfer between the jet expansion and the bulk flow. As the dimensions of the fan are normally fixed, only increasing the jet velocity it is possible to raise the discharged thrust. Unfortunately, this leads to a higher electrical consumption, compromising the thrust-power ratio. With this constraint, typical designs maximize this ratio limiting the jet velocity to moderate values between 30 to $35 \mathrm{~m} / \mathrm{s}$ in the case of fans with an outer diameter of 1200 or $1400 \mathrm{~mm}$.

In the present investigation, an axial jet fan of high thrust-power ratio designed by the authors has been modeled to analyze the tip leakage vortex. Figure 2 shows the elliptic profiles for 15 radial positions of the rotor blades. The origin of coordinates is placed on the blade stacking axis. The design specifications of the jet fan can be resumed as follows: tip diameter, $1200 \mathrm{~mm}$; nominal flow rate, $31.4 \mathrm{~m} / \mathrm{s}$ and thrust, $900 \mathrm{~N}$. A $22 \mathrm{~kW}$ fan-driving motor is placed inside the hub (inner diameter of $440 \mathrm{~mm}$ ), rotating at $1470 \mathrm{rpm}$. The hub 
is covered with a non-rotating nose fairing at both inlet and outlet planes of the fan to assure an inflow as uniform as possible. The rotor has 8 blades with $380 \mathrm{~mm}$ of span, and a hub-to-tip ratio of 0.36 . The blades were designed to obtain a free-vortex distribution of the tangential velocity at the impeller exit. The geometrical parameters of the airfoils at hub, midspan and tip sections are summarized in table 1.

At the single operating point, the fan has a design flow coefficient of $\phi=0.34$ (based on tip speed). The Reynolds number (based on the relative inlet velocity and the chord length at tip radius) is $1.3 \times 10^{6}$. The rotor presents a $5 \mathrm{~mm}$ tip clearance, that is a $2.56 \%$ of tip chord length or $1.3 \%$ of blade height. More details of the design can be found in [17].

\section{EXPERIMENTAL FACILITY AND RESULTS}

\subsection{Experimental facility.}

The schematic view of the experimental setup is shown in figure 3 . This open-loop facility includes two bell-mouth sides, and six struts to fit the inner fan-motor assembly to the outer shroud of 3.9 meters long (three struts are located upstream the rotor and the other three are placed downstream). In the nominal operating mode, there is also a semispherical diffuser at the jet fan inlet. The whole jet fan is cantilevered from an external structure in order to measure the actual thrust by means of an axial dynamometer.

It must be pointed out that the operating conditions in the laboratory are slightly different from those developed in-site. In particular, the proximity of the cantilevered fans to the ceiling or the typical streamwise velocities of $2-3 \mathrm{~m} / \mathrm{s}$ established in the bulk flow in the tunnel may modify the uniform inlet conditions of the fans. Also, it is well-known that a pressure gradient between both end sides of the tunnel, even a very small one, has a 
major role on the performance of a longitudinal ventilation system [18], but mainly on the transfer momentum of the jet expansion rather than on the local aspirating conditions of the fans. Therefore, it is assumed that these effects have an impact on the jet expansion, but no significant influence on the jet fan passage flow.

An experimental characterization of the passage flow has been conducted using hotwire anemometry. In particular, the wake flow and the shear layers associated to the rotor wakes were captured with a two hot-wire anemometer. The anemometric probe was composed by two tungsten filament wires of $5 \mu \mathrm{m}$ dia, in a $120^{\circ}$ crossed layout, with output signals connected to a TSI IFA-100 anemometer. The angular uncertainties are estimated in $2^{\circ}$, so relative uncertainty for velocity measurements are between 0.9 and $1.3 \%$ [19]. It has been considered a temporal resolution of fifty measurement points for every rotor passage, thus giving an acquisition frequency of $9.81 \mathrm{kHz}$. A low-pass filter of $5 \mathrm{kHz}$ has been implemented to reduce uncertainty. This filter is high enough to capture deterministic phenomena (blade passing frequency at design speed is $196 \mathrm{~Hz}$ ) and avoid aliasing troubles. Also, a trigger was needed to match blade passing periods, so ensembleaveraged distributions could be obtained from instantaneous raw data.

The probe was installed in a supporter traversing system, so different radial positions were measured upstream and downstream the rotor. Because there are no vortical or potential interactions with other mechanical elements (no stator, and struts are supposed to be placed far away from the blades), the flow is axisymmetric. Therefore, it is no necessary to measure at several tangential locations: the temporal evolution in the absolute frame of reference for any position is directly related to the circumferential gradients in the relative frame of reference according to $\partial / \partial t=-\omega \partial / \partial \theta$. Figure 3 also shows a front view of the jet fan discharge with the probe fixed in the measurement location, 120 $\mathrm{mm}$ downstream the airfoil trailing edge ( $180 \%$ of axial chord from leading edge). 
The measuring procedure was split in 45 blocks. Every block of data was obtained by acquiring the velocity fluctuations for 5 rotor turns ( 40 blade passages) during five minutes. It was necessary to capture so much data because of an inherent low-frequency fluctuation in the mass flow rate, due to unsteady environmental conditions. At that point, an ensemble-averaged procedure was introduced in order to filter all the temporal scales non-related with the machine rotor period. Finally, representing the ensemble data in the relative frame of reference, all the experimental data was reduced into figures $4(a)$ and $4(b)$.

\begin{tabular}{lccc}
\hline \hline & Hub & Midspan & Tip \\
\hline Radius $(\mathrm{mm})$ & 220 & 410 & 600 \\
\hline Chord length $(\mathrm{mm})$ & 199.8 & 201.9 & 195.2 \\
\hline Solidity & 1.15 & 0.62 & 0.41 \\
\hline Stagger angle $(\stackrel{\circ}{)})$ & 28.37 & 55.76 & 66.91 \\
\hline Camber angle $(\stackrel{\circ}{)}$ & 0.0 & 0.0 & 0.0 \\
\hline Thickness-to-chord ratio $(\%)$ & 11.4 & 9.0 & 7.7 \\
\hline Pitch $(\mathrm{mm})$ & 172.8 & 322.0 & 471.2 \\
\hline Inlet relative flow angle $(\stackrel{\circ}{)})$ & 46.55 & 63.06 & 70.86 \\
\hline Outlet relative flow angle $(\stackrel{\circ}{)}$ & 28.39 & 26.7 & 27.38 \\
\hline
\end{tabular}

Table 1. Design parameters of the jet fan rotor.

\subsection{Experimental results.}

Basic structures of the flow downstream of the rotor are presented in a transversal plane at the $150 \%$ of axial chord from the leading edge. Figure $4(a)$ shows an ensembleaveraged representation of the axial velocity, normalized by the overall mean value; while figure 4 (b) shows the tangential component, normalized by the blade tip velocity. Both distributions, measured with the anemometric probe, have been replotted tangentially over 
a second rotor pitch (relative reference frame), since the flow is periodic in the pitchwise direction. At approximate angular positions of 0.2 and 1.2 of the rotor pitch, the wake structure is clearly observed in the axial velocity distribution. Also, the decay in velocity is more pronounced from midspan to hub sections, due to the major blade thickness in there; while the core region is clearly uniform both span and pitchwise (values of 1.08 elsewhere). High-velocity zones are also observed towards both pressure and suction sides, especially in the tip region, beneath the casing layer.

Figure 4(b) shows how major values of tangential velocity are placed in the zones affected by the wakes. In the core region, there is a reduction in the component from hub to tip, as expected from the free vortex design of the blades. At hub sections, the decay in tangential velocity spreads circumferentially from the wake center, resulting in a large blockage. This implies a major flow separation at hub sections. On the other hand, near the tip region, the tangential velocity is increased in the wake structure. This high-velocity region (values of 0.11 ) has no correspondence in the axial velocity distribution, so its origin suggests a possible interference of the wake shear layer with the tip vortex.

A representative temporal evolution of the velocity components for one rotor revolution is plotted in figure 5 . Thus, a single realization of the ensemble-averaged data is shown at the midspan and in the tip region. At midspan, a regular wake-core distribution is observed in the axial velocity. As expected, maximum values of the tangential velocity are in phase with axial velocity decays. The deficit in axial velocity is progressively reduced spanwise because of the lower aerodynamic loads of the blades at external radial positions. But in the tip region (90 and $97 \%$ of the span), the flow structures loss uniformity and the trace of the wakes is masked by random turbulence. In addition, at $97 \%$ of the span, the axial velocity mean value is drastically reduced due to the influence of the casing boundary layer. 


\section{NUMERICAL SIMULATION}

The commercial CFD software FLUENT v6.2 was used to solve the Navier-Stokes set of equations. This $3 \mathrm{D}$, viscous code, introduces a cell-centered volume finite method with second-order upwind schemes for convection and diffusion terms. A SIMPLE algorithm is chosen for the pressure and velocity coupling. The continuity and momentum equations for a three-dimensional flow are:

$$
\begin{gathered}
\partial_{t} \rho+\nabla \cdot(\rho \vec{v})=0 \\
\partial_{t}(\rho \vec{v})+\nabla \cdot(\rho \overrightarrow{v v})=-\nabla p+\nabla \cdot \tau
\end{gathered}
$$

where $\vec{v}$ is the velocity vector, $\tau$ is the stress tensor and $p$ is the static pressure. Body forces and all other possible source terms are neglected.

Since the flow is periodic every blade passage in the pitchwise direction, a set of periodic boundary conditions were introduced in the geometry allowing just one passage of the fan rotor to be modelled (figure 6). Consequently, the blade passage description can be extraordinary enhanced through high density meshes at affordable computational costs (even to include tip clearance modeling). The numerical domain is extended one blade chord upstream and three blade chords downstream to guarantee flow uniformity at inlet/outlet axial locations.

A radial distribution of inflow velocity (measured experimentally) has been set as the inlet boundary condition for the computations. The boundary layer displacement thickness $\delta_{1}$ and momentum thickness $\delta_{2}$, normalized by the blade span $\mathrm{h}$, have been calculated for both hub and tip boundary layers at the rotor inlet (one chord upstream - table 2). The 
shape factor $\mathrm{H}_{12}\left(=\delta_{1} / \delta_{2}\right)$ at both endwalls, 1.75 for the tip and 1.93 for the hub, reveals that the tip boundary layer is more developed into the turbulent regime than the hub one, still conditioned by the proximity of the nose fairing. Complementarily, a uniform turbulence level of $2.5 \%$ (according to the available experimental data) was fixed for a turbulent length scale of $0.1 \mathrm{~m}$ (typically, a fraction of the casing diameter). At the outlet, a radial distribution of total pressure, measured at the jet fan discharge has been used to estimate the static pressure distribution imposed in the numerical modelling. It has been observed that such distribution is significantly different to the one obtained from a radial equilibrium assumption, which is an indicator of the importance of secondary flows in this type of jet fans.

\begin{tabular}{lcc}
\hline \hline & Hub boundary layer & Tip boundary layer \\
\hline Inlet displacement thickness, $\delta_{1} / \mathrm{h}(\%)$ & 3.54 & 5.11 \\
\hline Inlet momentum thickness, $\delta_{2} / \mathrm{h}(\%)$ & 1.83 & 2.90 \\
\hline Inlet shape factor, $\mathrm{H}_{12}$ & 1.93 & 1.75 \\
\hline
\end{tabular}

Table 2. Casing wall boundary layer integral parameters at the rotor inlet.

In the present case, there are no stator vanes or fixed elements interacting with the rotor blades, so a simulation with a moving reference frame for the rotor passage is sufficient. However, grid interfaces have been introduced in the geometry to allow the inclusion of a non-conformal grid, which is simpler to implement. In order to generate efficient meshing and avoid highly skewed elements, a hybrid meshing strategy has been followed with the commercial grid generator GAMBIT v2.2. As observed in figure 2, the large hub-to-tip torsion of the blades prohibits a complete radial extrusion of the mesh in the passage. In addition, the pitch differences from hub to tip would lead to excessive grid deformations in the tangential direction. Therefore, fully structured blocks have been extruded spanwise just in the blade proximity, while tetrahedral elements were applied in the rest zones 
(figure 6). In addition, in the tip clearance region, triangular-based prismatic cells were used to obtain a better gridding gap. The total number of elements for the whole geometry

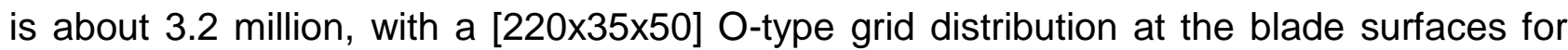
the span height. Figure 6 also shows in detail the 12-nodes radial distribution adopted in the tip clearance. As a result, a non-dimensional wall distance $\mathrm{y}^{+}$of 12 was achieved at the tip endwall, while averaged $\mathrm{y}^{+}$values of 50 were obtained at both suction and pressure side of the blades. This mesh density has been chosen to obtain an accurate spatial discretization. Fixing these values of $\mathrm{y}^{+}$, it is necessary to implement near-wall modelling using logarithmic wall functions (wall-adjacent cells are not placed in the buffer layer) in both blade surfaces and end-wall casings. In particular, non-equilibrium wall functions were finally employed to take into account the complexity of the wall-bounded shear layers in the tip clearance.

Both steady and unsteady simulations have been executed over dual-processor PC's, 3.2 $\mathrm{GHz}$, with $1.5 \mathrm{~Gb}$ RAM. The computations are parallelized with a Gigabit connection set. In the case of the unsteady computations, a second-order accurate scheme was introduced for the temporal discretization, with minimum time steps in the order of $10^{-5} \mathrm{~s}$. This election represents a frequency resolution of $60 \mathrm{kHz}$, meaning that time scales for vortex shedding in this jet fan (expected to be developed at $4-6 \mathrm{kHz}$ for a Strouhal number in the range of 0.2 ) could be recovered in the simulation. However, it has been observed that using URANS schemes, small-scale turbulence associated to vortex shedding or tip vortex oscillations [20] cannot be resolved numerically. These "unresolved" scales of the flow are still far beyond affordable spatial and temporal discretizations for engineering applications with Reynolds-averaged equations. As a consequence, no unsteady features of these flow structures could be captured and final results and conclusions have been derived from steady calculations, which provide an accurate description of the basic, primary details of the flow patterns. Valuable information about the turbulence intensity 
can be still estimated through the analysis of the fluctuating parts in the Reynolds Stresses terms.

With the assumption of a moving reference frame, the rotor domain is frozen, while fixing a characteristic rotation of 1470 rpm around the axis. In addition, the casing velocity is set to zero, referenced to the absolute frame. This procedure avoids the inclusion of additional interfaces at the tip gap, so model complexity is reduced.

\section{Turbulence modelling.}

The choice of turbulence modelling remains still the most critical item when dealing with RANS computations of tip-leakage flows [21]. The prediction of tip vortex core size, its evolution along the rotor passage, the vorticity strength and details about the tip gap velocity and turbulence fields, are major issues that must be correctly addressed. Therefore, the use of advanced turbulence models (preferably second-moment) is mandatory to resolve these phenomena accurately. However, due to the great computational effort associated with second-moment closures (Re-stress models), EddyViscosity Models are still a good choice to consider.

In the present work, a comparison between different RANS models has been performed in order to check their reliability and potentiality for this problem. In particular, SpallartAllmaras one equation model (S-A), k-epsilon (K-E) and k-omega (K-W) two equations models, as representative of Eddy-Viscosity Models; and Reynolds Stress Model (RSM), as second-moment closure, have been tested for this particular jet fan. Figure 7 shows a comparison of global results obtained with each particular model respect to the experimental velocity profile measured at the jet fan discharge. In essence, both S-A and RSM models present a good agreement, though endwall boundary layers are underpredicted. On the contrary, K-W presents a clear deviation on the mean velocity, 
which indicates an even more unrealistic prediction of the displacement thickness in the casing. Also, K-E model cannot follow the velocity profile towards the hub, where secondary flows tend to increase the velocity distribution.

Additionally, the total-to-total pressure rise predicted by every turbulence model has been compared to experimental data (table 3). Also, the hydraulic efficiency is computed, and compared to the design value, through the ratio between the hydraulic power (mass flow rate multiplied by the total pressure rise) and the mechanic power (net torque of the rotor times the rotational speed). As expected, slight differences are observed for both S-A and RSM models. Large deviations are found for both K-E and K-W models, especially in the estimation of the hydraulic efficiency. This is a clear indicator that two-equation models resolve poorly the boundary layers, especially those of the rotor blades, so the calculation of the tip vortex has to be very compromised.

\begin{tabular}{lccccc}
\hline & S-A & K-E & K-W & RSM & EXP \\
\hline$\Delta P(\mathrm{~Pa})$ & 583 & 565 & 547 & 581 & 575 \\
\hline$\eta(\%)$ & 83.4 & 75.3 & 62.1 & 84.7 & 86 \\
\hline
\end{tabular}

Table 3. Pressure rise predictions.

On the other hand, it is expected that not only global, but also local characteristics of the flow structure (in particular, the leakage flow) are better captured with the RSM model, due to its anisotropic assumptions and high-order formulations. Then, present investigations have been carried out using the RSM model. In particular, a RSM modelling based on the linear pressure-strain scheme with the classical set of model constants has been employed. Wall-reflection effects have been disabled on the pressure-strain sub-model because it is known that they do not improve the accuracy of RSM predictions for flows involving multiple walls or walls with significant curvature (e.g., an axisymmetric passage). 
The individual Reynolds stresses and the turbulent dissipation rate near the walls have been computed using non-equilibrium wall functions based on the local turbulent kinetic energy. For the inlet boundary conditions, these quantities are derived from the turbulence intensity level and the characteristic length scale specified above, assuming isotropy of turbulence. A detailed analysis of the leakage flow computations in a reversible jet fan operating at design conditions is discussed below. Future work will be focused on the advantages and drawbacks of CFD predictions using simpler turbulence models.

\section{RESULTS AND DISCUSSION}

\section{Flow structure.}

From the visualizations of the numerical results, it has been observed that an interference zone is established between three flow structures inside the rotor passage. A low velocity region, derived from the stagnation conditions of the adjacent blade, is concentrated towards the suction side of the blade, interacting with the vortical structures of the leakage flow. In the tip clearance, the establishment of the well-known tip leakage vortex is complemented with the presence of a tip separation vortex, induced by the flow separation at the trailing edge.

Furthermore, the impact of this interaction modifies the detached conditions of the wake shear layer in the suction side, affecting its mixing out mechanism and enlarging the suction wake. These observations, schematically shown in a cartoon picture in figure 8 , constitute a classical approach, previously reported by several authors in the literature like Kang et al. [7] or Inoue et al [10]. They are presented below, starting with primary flow patterns in the rotor passage, and concluding with a detailed analysis of the leakage flow. 


\section{Rotor wake analysis.}

Figure $9(\mathrm{a})$ is introduced to compare the numerical results and the experimental distribution shown in figure 4(a). For that purpose, the same transversal plane used in the experimental campaign has been chosen in this analysis, $120 \mathrm{~mm}$ downstream of the rotor trailing edge. To facilitate the comparison, the representation of the axial velocity, normalized by the overall mean value, has been duplicated tangentially, including two rotor pitches. As previously seen, the major differences are placed in the thickness of the boundary layers, numerically underpredicted. Table 4 summarizes the integral parameters of hub and tip boundary layers at the rotor exit. These values have been obtained through a pitch-wise averaging of the axial velocity map in the outlet plane. Effectively, the displacement thickness predicted by the code in both inner and outer casings is lower that that calculated from the experimental data. However, such discrepancies may arise from a rough estimation of the experimental distribution, so more measuring locations close to the end-walls would have been desirable to enhance the comparison. At the hub, the shape factor is lower than in the tip because the velocity deficit imposed by the rotor wakes influences the development of the boundary layer (the values of the displacement thickness are significantly large). Also, the differences in the hub shape factor between the numerical predictions and the experiments are probably due to the influence of secondary flows, barely captured in the measurements.

\begin{tabular}{lcccc}
\hline \hline & \multicolumn{2}{c}{ Hub boundary layer } & \multicolumn{2}{c}{ Tip boundary layer } \\
& EXP & NUM & EXP & NUM \\
\hline Outlet displacement thickness, $\delta_{1} / \mathrm{h}(\%)$ & 6.57 & 5.90 & 2.83 & 1.98 \\
\hline Outlet momentum thickness, $\delta_{2} / \mathrm{h}(\%)$ & 4.34 & 3.41 & 1.14 & 0.91 \\
\hline Outlet shape factor, $\mathrm{H}_{12}$ & 1.51 & 1.72 & 2.47 & 2.16 \\
\hline
\end{tabular}

Table 4. Casing wall boundary layer integral parameters at the rotor outlet. 
On the contrary, a reasonable agreement is observed in the inner zones of the passage, with high-velocity regions established in coherent locations with respect to the experimental data. Additionally, in the hub sections, the wake intensity is increased, due to the proximity of the blades trailing edge. Since a high-velocity zone is linked to the suction side of the wakes in the tip region, the flow structure suggests the presence of a flow blockage in the passage, induced by the impact of the tip vortex on the blade boundary layers (discussed below).

Complementarily, the trends observed in the tangential velocity are consistent with the experiments, showing an overall coherency between both experimental -fig. 4(b)- and numerical results -fig. 9(b)-. As expected, the tangential velocity (normalized by the tip speed) follows the free-vortex design. Thus, the distribution of the circumferential velocity decreases exponentially in the radial direction, at mid-passage locations. On the contrary, wake-affected zones exhibit major values, especially near the hub. The broadening of the blade wakes in the inner half of the passage is derived from major thickness of the elliptic profile. At the tip, there are also high values of tangential velocity, suggesting that the flow field in the outer half of the flow passage is dominated by the tip vortex. The casing viscous region becomes thicker because of the diffusion of the tip leakage vortex.

\section{Passage flow structure.}

The analysis of the flow structure inside the blade passage is illustrated in figure 10 for different streamwise locations. The positions of the transversal planes have been chosen as a fraction of the blade chord in the blade tip. The first distribution, at $s / c=10 \%$, shows the radial effect of the stagnation pressure in the axial velocity distribution. As a result of the high three-dimensionality of the blade leading edge (see figure 2), a sharp low-velocity 
region is generated towards the pressure side. This shadow region of axial velocity extends completely from hub to tip. At midchord $(\mathrm{s} / \mathrm{c}=50 \%)$, this region has been shifted tangentially, so it is now placed at the midpassage. The tip leakage vortex is also observable in the midchord distribution, moving towards the low-velocity zone. Consequently, the tip vortex structure interacts with the low-velocity region, modifying the throughflow structure and concentrating the axial velocity defect in the passage, as shown at $\mathrm{s} / \mathrm{c}=75 \%$. Notice the tip leakage vortex located between the huge low-velocity zone and the casing boundary layer. When the flow reaches the blade trailing edge $(\mathrm{s} / \mathrm{c}=100 \%)$, the tip vortex has overcome the low-velocity region, moving towards the pressure side. On the other hand, the low-velocity zone is interfacing with the detached conditions of the flow in the suction side. Due to the particular characteristics of the elliptic profiles, the flow separates in both pressure and suction sides, enlarging the wake and the momentum deficit within it. However, the effect of the low-velocity region in the suction side boundary layer enlarges the suction wake, as can be observed at $\mathrm{s} / \mathrm{c}=130 \%$. In addition, the highaxial velocity close to the pressure side in the tip is controlling the thickness of the wake shed from the pressure side. As a consequence, the high-velocity region penetrates inside the enlarged wake $(s / c=150 \%)$, and the pressure wake is rapidly diffused into the mean throughflow.

Definitively, figure $9(\mathrm{a})$ is the final stage for the evolution of the axial velocity along the blade passage summarized in figure 10. It was shown that the central blockage is due to the presence of a low-velocity region, which is generated at the blade leading edge, modified by the tip leakage vortex, and responsible for the growth of the detached boundary layer in the suction side. Similar findings were observed by Zhu et al. [15] in an axial ventilation fan where the "mixing interaction between the tip leakage flow and the main flow produces a low axial velocity region in the tip, leading to the blockage of the main flow". The residual of the tip vortex is a high-velocity region that controls the width of 
the blade rotor wake at the tip, while maximum wake thickness is developed near the hub section.

\section{Tip leakage vortex.}

The influence of the tip vortex on the blade pressure is also demonstrated in the suction side contours in figure 11. The figure shows the mean pressure coefficient, computed on the blade surfaces. As a result, the pressure distribution near the tip differs considerably from that near the midspan. Particularly, on the suction side, the pressure near the tip tends to be lower, especially in that zone affected by the vortex (vortex influence in fig. 11). Toward the trailing edge, the pressure becomes similar to the midspan distribution. Anyway, the presence of the tip vortex on the suction side is changing significantly the spanwise distribution: pressure isolines are no longer aligned with the radial direction.

The total pressure loss coefficient $\left(\zeta_{L}\right)$ is a classical metric to track the evolution of the tip vortex within the blade passage. Figure 12 gives contour plots of the loss coefficient at various axial positions. This coefficient is defined as the difference between the local total pressure and the inlet total pressure, made non-dimensional by the inlet dynamic pressure. A typical structure of the total pressure loss core associated to the tip vortex is captured by the numerical model, with a magnitude and progressive mixing that it is in consonance with previous results found in the literature. For instance, Basson et al. [22] presented similar distributions of the loss coefficient in the tip vortex, with maximum values around -3 to -4 in the core, at $85 \%$ axial chord from the leading edge. Other authors, like Lakshminarayana et al. [9] defined an alternative relative total pressure loss coefficient to analyze losses in the wake region of an axial compressor, with typical values around $-0,4$ in tip clearance. Kang et al. [7] and Bae et al. [23] also found similar vortical structures with values between -0.5 and -0.6 of the loss coefficient in linear cascades at $120 \%$ and $105 \%$ 
axial chord from the leading edge, respectively. Notice that the values obtained in the figure are very high due to the normalization by the inlet dynamic pressure, based on the averaged inflow velocity (aprox. $32 \mathrm{~m} / \mathrm{s}$ ). If they were computed based on the relative freestream velocity in the tip (around $100 \mathrm{~m} / \mathrm{s}$ ), the scale will be much lower (almost one order of magnitude) in the range of Kang or Bae et al. results. In the figure, the trajectory of the tip vortex is clearly noticeable. Additionally, the tip leakage flow can be observed coming from the pressure side along the whole blade chord at $\mathrm{s} / \mathrm{c}=25 \%$. The leakage jet flow is weak near the leading edge, but becomes stronger in the downstream direction, and is the strongest in the midchord. Therefore, the leakage flow is rather narrow in the forward half of the blade passage and grows rapidly in the downstream half. Meanwhile, the tip vortex broadens along the axial coordinate, and moves tangentially toward the pressure side of the adjacent blade.

The evolution of the locus of the leakage vortex center is also shown in a composition in figure 13. Firstly, the structure of the tip leakage flow is illustrated above with the identification of the vortex sheet that leads to the establishment of the rolling-up mechanism. This is observed in a qualitative picture that gives an idea of the size and trajectory of the tip vortex. Next, the center of the maximum helicity trough is determined quantitatively along the streamwise direction, inside and outside the blade passage. Since intrinsic coordinates of the blade passage have been employed in a regular, orthogonal grid, a geometric distortion has been introduced in the plot. The origin of the tip vortex trajectory is located at $15 \%$ of the axial chord of the blades. At the exit of the blade passage, the tip vortex has been transported in the throughflow, so the locus has moved a $60 \%$ percent of the rotor blade pitch. On the contrary, in the axial direction there is no significant motion of the vortex locus spanwise, as observed on the projection of the trajectory in the vertical planes. At $150 \%$ of the axial chord, the tip vortex has completed its motion along the rotor pitch, so it is placed just downstream of the trailing edge in the 
adjacent blade. At this point, it was previously discussed (last picture in fig. 10) how the tip vortex modifies the structure of the wake in the consecutive blade. In this case, at $\mathrm{s} / \mathrm{c}=150 \%$, due to the high-three dimensionality of the blade trailing edge, the tip vortex of an adjacent blade interacts with the wake shear layer in the tip region, while the flow is still leaving the passage in the hub region (the transversal plane splits the blade in the hub section - see fig.10). Therefore, there is an influence of the adjacent tip vortex into the flow patterns of the next blade passage, because of the motion of the vortex through a significant portion of the span of that consecutive blade. This phenomenon has been observed in axial compressors with high solidities and large tip clearances, where the leakage flow region reaches the adjacent blade row [10]. In the present case, the influence of the large tip clearance is dominant, though the jet fan presents a low solidity (table 1).

Figure 14 shows a rear view of the evolution of helicity contours along the blade passage. This scalar variable is useful to describe flow fields with helical behavior, like the tip vortex structure. As discussed in figure 13, the locus of the tip leakage vortex center is placed above the $95 \%$ of the blade span. Then, the transversal planes in figure 14 are just showing the helicity maps from the $85 \%$ of the blade span to the outer casing of the jet fan. In the rest spanwise locations, the helicity values can be neglected. Mathematically, the helicity is defined as the projection of the vorticity over the velocity vector. Then, a nondimensional helicity can be formulated dividing by the averaged axial velocity and the rotational speed of the fan, leading to:

$$
H^{*}=\frac{\vec{v} \cdot \vec{\omega}}{v_{0} \Omega}=\frac{\vec{v} \cdot(\nabla \times \vec{v})}{v_{0} \Omega}
$$

From figure 13 , it was shown that at $\mathrm{s} / \mathrm{c}=15 \%$, the leakage vortex sheet is shed from the suction side of the blade. Therefore, the first distribution in figure 14 , at $\mathrm{s} / \mathrm{c}=25 \%$, shows 
the initial roll-up mechanism of the tip vortex at its infancy. Later, at s/c=37\%, the tip vortex is well-established, with maximum non-dimensional values of -10 . It is noticeable that the helicity distribution appears quite stretched in the tangential direction, because of the relative position between the transversal planes and the trajectory of the vortex center. If representative planes were placed normal to the locus trajectory, then the helicity distribution would be quite circular. Otherwise, the helicity map is more stretched as the tip vortex trajectory separates from the axial direction. The negative sign in the distributions reveals opposite senses for both velocity and vorticity vectors. This means that the vorticity vectors are pointing upstream, since velocity direction is mainly aligned streamwise. As a result, the tip vortex is rotating counter-clockwise (theory states that vorticity and local rotation present opposite signs). Maximum values of helicity in the tip leakage vortex are obtained at the midchord $(\mathrm{s} / \mathrm{c}=50 \%)$, so it is confirmed that maximum leakage flow is reached at central positions, as expected from the results in figure 12 . At $s / c=63 \%$, the tip leakage vortex weakens and spreads tangentially, while near the suction side a new vortex is beginning to roll-up. Intermediate positions, at $\mathrm{s} / \mathrm{c}=75 \%$ and $\mathrm{s} / \mathrm{c}=90 \%$, are confirming the tangential motion and decay of the tip leakage vortex and the generation of a tip separation vortex. This second vortex is associated to the flow separation at the tip, as derived from the position of the vortex shedding (at $\mathrm{s} / \mathrm{c}=90 \%$ is well-formed and practically shed from the suction side). Similar vortex patterns can be found in [5], with a classic schematic of the vortex structure with both tip separation and tip leakage vortices. At $s / c=130 \%$, the residual of the tip separation vortex presents a moderate value of -6 . The negative value points out that tip separation vortex is also rotating counter-clockwise.

In addition, at this axial location, the tip leakage vortex has been transported along the whole blade pitch, so the tip leakage vortex from the previous blade is positioned now at the pressure surface. At $\mathrm{s} / \mathrm{c}=150 \%$, the tip separation vortex is practically diffused on the casing boundary layer, while the tip vortex from the adjacent blade has been regrouped. 
Figure 15 shows axial velocity isolines distributions on cylindrical surfaces at different radial immersion along the blade span. At midspan, there is a typical contour for a lowspeed axial fan, with a controlled stagnation point and a well-defined blade loading on the suction side of the profiles. There is also a thick wake associated to the flow separation at the trailing edge. At the $75 \%$ of the span, the distribution presents no significant changes respect to the previous one at midspan, except for the growth of the stagnation zone and an initial displacement of the blade loading in the suction side towards the trailing edge. At the $90 \%$ of the span, the blade loading is completely distorted by the effect of the leakage flow. As a consequence, axial velocity is increased along the downstream half of the blades suction surface, due to the effect of the driven jet flow across the tip gap. At the same time, there is a reduction in the velocity on the pressure side near the leading edge. Thus, the axial velocity distribution is split in the pressure side generating a high-velocity region that connects with the suction side maximum velocities. At the $95 \%$ of the span, this trend is completely confirmed, because of the establishment of a clear path of high-velocity going from the suction side of a blade to the pressure side of the adjacent one (marked in the figure with dashed lines). Complementary, the stagnation region is drastically increased, while the wake zone is also modified by the high-velocity path that is followed by the tip leakage vortex.

\section{Turbulence intensity.}

Figure 16 compares the turbulence intensity associated to the axial velocity at the $180 \%$ of the tip axial chord, at several spanwise locations. At midspan, there is an extremely low value of fluctuation (aprox. 3\%), pointing out the stable behaviour of the flow patterns in there. As the radial direction is increased, the level of turbulence becomes higher. Undoubtedly, maximum variations appears associated to the unstable flow structures of 
the tip leakage vortex on the wake-affected zone rotor downstream (up to $25 \%$ ). Jang et al. [14] reported "high velocity fluctuations near the blade suction surface" in an axial flow fan due to the tip leakage vortex disturbing the formation of the wake fluid.

Nevertheless, at $90 \%$ of the span, there is a calmed region, derived from the different position of the residual tip leakage vortex and the minimum value of the rotor wake near the tip (value of 1.00 in figure $9(\mathrm{a})$ ). These distributions can be compared to the experimental instabilities of the velocity signals in figure 5, which are severely increased along the radial direction.

Also, the axial evolution of pitch-wise resolved turbulence intensity (maps in figure 17) reveals how the turbulence levels are severely increased towards the end-wall boundary layers when compared to the midspan sections. As expected, maximum turbulence is developed in the tip clearance, linked to the tip vortex shedding. At the hub, the mixing-out of the rotor wakes is clearly contributing to develop a large region with significant levels of turbulence. At the tip, the high turbulence associated to the tip vortex is up to a $15 \%$, even one blade chord downstream of the rotor trailing edge for pitch-averaged distributions. In addition, averaging these pitch-wise distributions, it is possible to address the passage through flow in terms of turbulence intensity (plots in the figure). Hence, the thickening of the casing boundary layers contributes to increase the turbulence level at the jet fan discharge, from a uniform $2.5 \%$ at the inlet to a radial distribution at the exit with moderate values at midspan (aprox. 3\%) but with high levels (up to 7\%) at the endwalls.

\section{CONCLUSIONS}

A three-dimensional numerical simulation of a monoplane axial jet fan with tip gap gridding has been discussed in this paper. The structure of the clearance flow and its 
influence on the mean throughflow has been clarified with the representation of averaged maps of non-dimensional velocity and helicity. The following conclusions are drawn from the numerical results shown in previous figures:

- A low-velocity region generated by the blockage of the blades leading edge penetrates into the blade passage, interacting with the tip leakage vortex shed by the adjacent blade. As a result, the low-velocity region is concentrated while moving toward the suction side of the blade, modifying the flow separation near the trailing edge.

- The simulation predicts the free vortex design of the blades, as derived from the coherency between both experimental and numerical distributions of relative tangential velocity at the rotor exit.

- The trajectory of the tip vortex has been illustrated with path lines released from the tip gap. Path lines have also revealed that the leakage jet flow is stronger at midchord. In addition, the locus of the tip vortex center has been determined from helicity distributions at different transversal locations along and outside the blade passage. The tangential motion of the tip vortex has been captured in the modeling, as well as its influence into the flow patterns of the adjacent blade passage, because of the motion of the vortex through a significant portion of the span of that consecutive blade.

- At the rotor exit, the tip clearance creates important levels of turbulence in the tip region. Maximum intensities near the casing (95 and $99 \%$ of the span) mainly consists in smallscale turbulence due to the diffusion of the tip leakage vortex. In addition, moderate fluctuations are encountered at $90 \%$ of the span due to the mixing of the shear layers shed in both pressure and suction sides of the blades. This generation of turbulence is a direct consequence of the flow separation at both sides in elliptic profiles.

Therefore, features of the tip clearance flow and the transport of the tip leakage vortex have been predicted by a commercial numerical code. The code presents an accurate 
global performance to predict swirl characteristics of the passage flow, and resolves the leakage flow in the tip gap gridded zone.

\section{ACKNOWLEDGEMENTS}

This work was supported by the Research Project "Characterization of Aerodynamic Noise due to the Interaction between the Rotor Blades and the Guide Vanes in Axial Flow Fans", ref. DPI2006-15720, MEC.

\section{REFERENCES}

1 Mutama, K.R., Hall, A.E. The Experimental Investigation of Jet Fan Aerodynamics using Wind Tunnel Modeling. ASME J.Fluids Engineering, 118 (2), 322-328, 1996.

2 Chen, T.Y., Lee, Y.T., Hsu, C.C. Investigations of piston-effect and jet fan-effect in model vehicle tunnels. Journal of Wind Engineering and Industrial Aerodynamics, 73 (2), 99-110, 1998.

3 Adamczyk, J.J.; Celestina, M.L. and Greitzer, E.M. The Role of Tip Clearance in HighSpeed Fan Stall. ASME Journal of Turbomachinery, vol. 115. pp. 28-39, 1993

4 Chen G.T.; Greitzer, E.M.; Tan, C.S.; Marble F.E. Similarity Analysis of Compressor Tip Clearance Flow Structure. ASME Journal of Turbomachinery. Vol. 113. pp.260-271, 1991 
5 Rains, D.A. Tip Clearance Flows in Axial Flow Compressors and Pumps. California Institute of Technology, Hydrodynamics and Mechanical Engineering Laboratories, Report No.5, 1954.

6 Storer, J.A.; Cumptsy, N.A. Tip Leakage Flow in Axial Compressors. ASME Journal of Turbomachinery, vol. 113. pp. 252-259, 1991.

7 Kang, S.; Hirsch, C. Experimental Study on the Three-Dimensional Flow Within a Compressor Cascade with Tip Clearance: Part I and II. ASME Journal of Turbomachinery, vol. 115. pp. 435-452, 1993.

8 Goto, A. Three-Dimensional Flow and Mixing in an Axial Flow Compressor with Different Rotor Tip Clearances. ASME Journal of Turbomachinery, vol. 117. pp. 336-347, 1992.

9 Lakshminarayana, B.; Zaccaria, M.; Marathe, B. The Structure of the Tip Clearance Flow in Axial Flow Compressors, ASME Journal of Turbomachinery, vol. 177. pp. 336-347, 1995.

10 Inoue, M.; Kurou, M. Structure of Tip Clearance Flow in an Isolated Axial Compressor Rotor. ASME Journal of Turbomachinery, vol. 111. pp. 250-256, 1989.

11 Stauter, R.C. Measurements of the Three-Dimensional Tip Region Flow Field in an Axial Compressor. ASME Journal of Turbomachinery, vol. 115. pp.468-476, 1993. 
12 Fukano, T.; Kodama, Y.; Takamatsu, Y. The Effects of Tip Clearance on the Noise of Low Pressure Axial and Mixed Flow Fans. Journal of Sound and Vibration, vol. 105, No.2, 1986.

13 Fukano, T., Jang, C.-M. Tip Clearance Noise of Axial Flow Fans Operating at Design and Off-design Conditions. Journal of Sound and Vibration, 275. pp. 1027-1050, 2004.

14 Jang. C.-M.; Sato, D.; Fukano, T. Experimental Analysis on Tip Leakage and Wake Flow in an Axial Flow Fan According to Flow Rates. ASME Journal of Fluids Engineering. Vol. 127. pp. 322-329, 2005.

15 Zhu, X.; Lin, W.; Du, Z. Experimental and Numerical Investigation of the Flow Field in the Tip Region of an Axial Ventilation Fan. ASME Journal of Fluids Engineering. Vol. 127. pp. 299-307, 2005

16 Van Zante, D.E.; Strasizar, A.J.; Wood, J.R.; Hathaway, M.D.; Okiishi, T.H. Recommendations for Achieving Accurate Numerical Simulation of Tip Clearance Flows in Transonic Compressor Rotors. ASME Journal of Turbomachinery, vol. 122. pp. 733-742, 2000.

17 C. Santolaria, R. Ballesteros, E. Blanco, J.L. Parrondo. Diseño aerodinámico de un ventilador de chorro reversible. Información Tecnológica, Vol. 7, № 4, pág. 133-140 (in Spanish), 1996.

18 Galdo Vega, M.; Argüelles Díaz, K.M.; Fernández Oro, J.M.; Ballesteros, R.; Santolaria, C. Numerical 3D simulation of a longitudinal ventilation system: memorial 
tunnel case. Tunnelling and Underground Space Technology, vol. 23 (5), pp. 539-551, 2008.

19 Blanco, E., Ballesteros, R.; Santolaria, C. Angular range and uncertainty analysis of non-orthogonal crossed hot wire probes. ASME Journal of Turbomachinery, vol. 123, pp. 90-94, 1998.

20 Tan, C.S. Unsteady Flows in Compressors. Effects of Aerodynamic Unsteadiness in Axial Turbomachines, Von Karman Institute Lecture Series, 2005.

21 Borello, D., Hanjalic, K., Rispoli, F. Computation of tip-leakage flow in a linear compressor cascade with a second-order moment turbulence closure. International Journal of Heat and Fluid Flow, 28, pp. 587-601, 2007.

22 Basson, A., Lakshminarayana. Numerical Simulation of Tip Clearance Effects in Turbomachinery. ASME Journal of Turbomachinery, vol. 117, pp. 348-359, 1995.

23 Bae J.W., Breuer, K.S., Tan, C.S. Active Control of Tip Clearance Flow in Axial Compressors. ASME Journal of Turbomachinery, vol. 127, pp. 352-362, 2005. 


\section{LIST OF FIGURES}

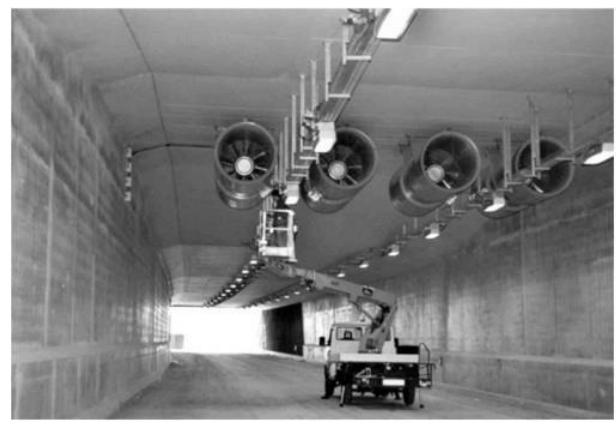

Jet fan cantilevered from the tunnel ceiling
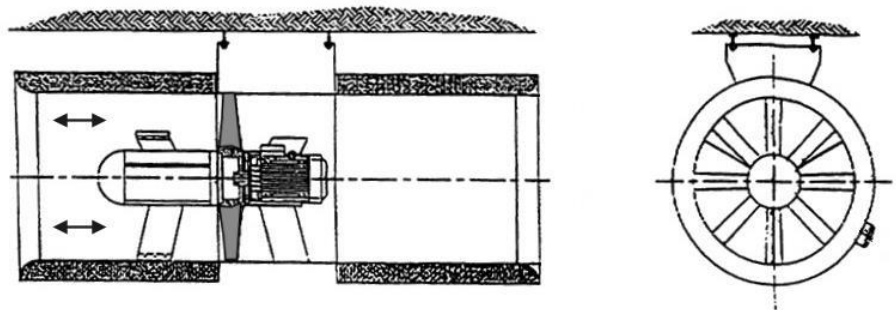

Fig. 1. Schematic of a typical jet fan in a road tunnel.
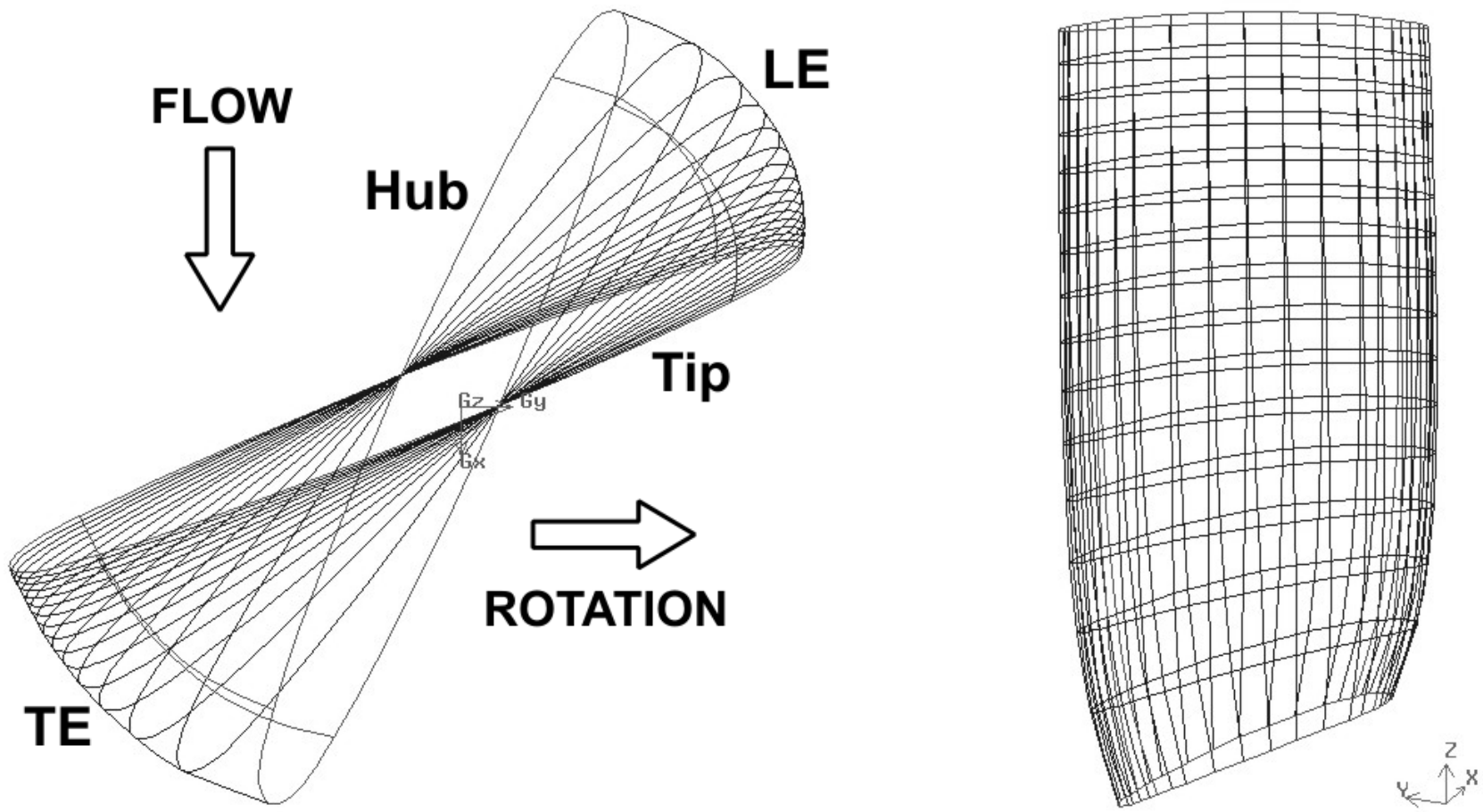

Fig. 2. Symmetric blade profile. 


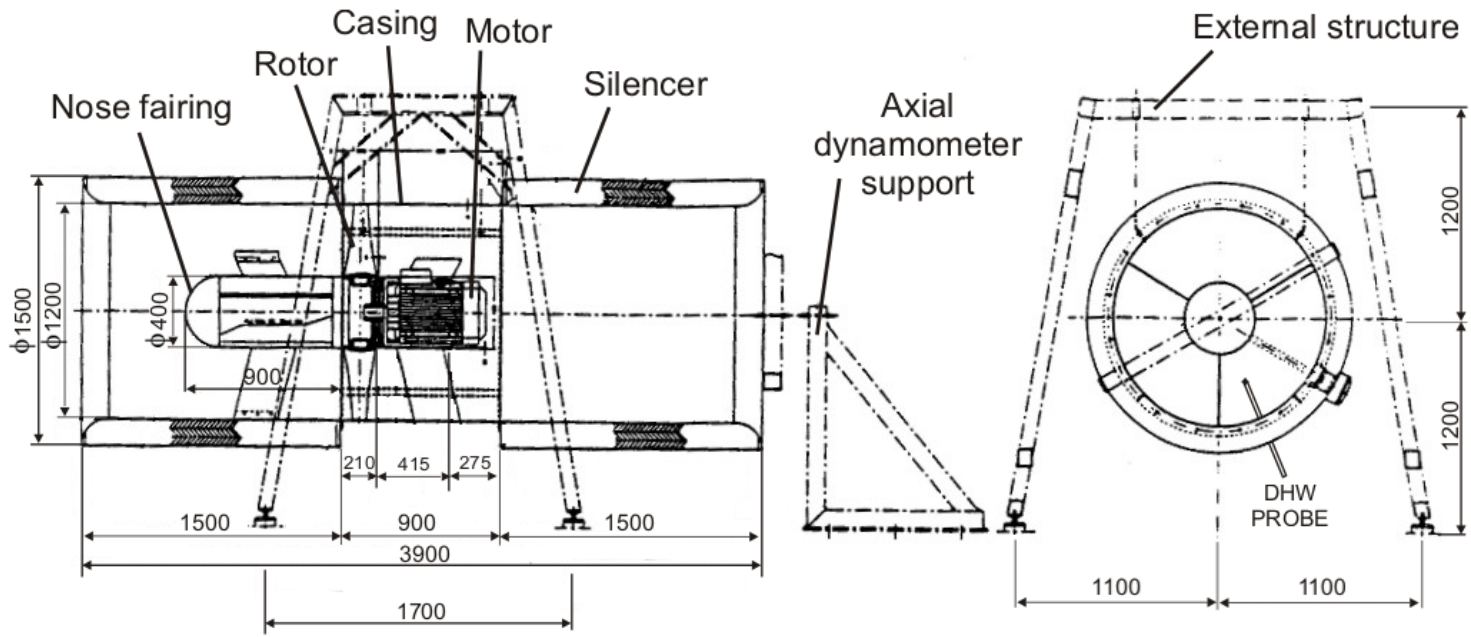

Fig. 3. Test-rig facility.
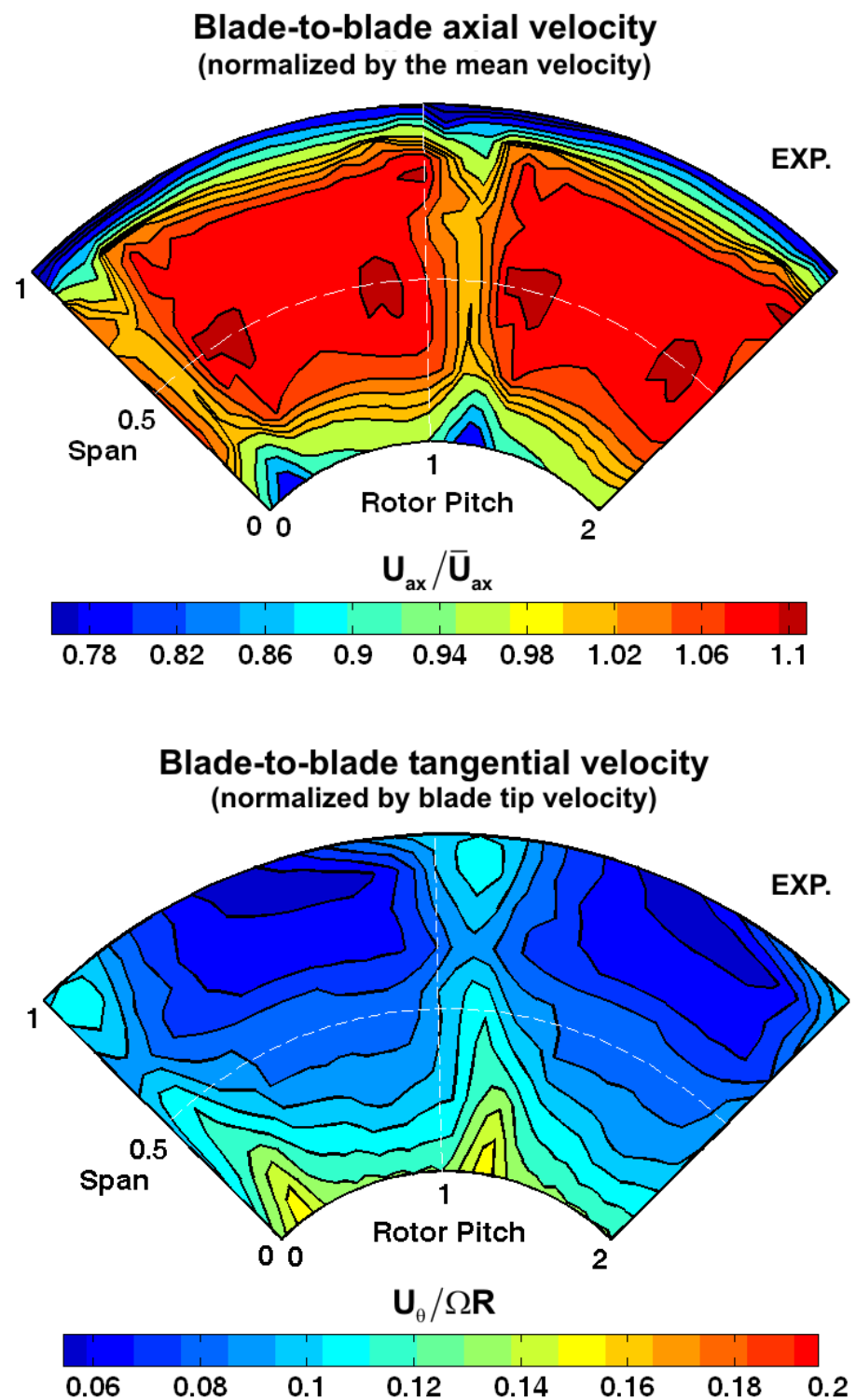

Fig. 4. Velocity distributions rotor downstream. (a) Axial. (b) Tangential. 
Ensemble-averaged Velocity

(Absolute frame reference rotor downstream)

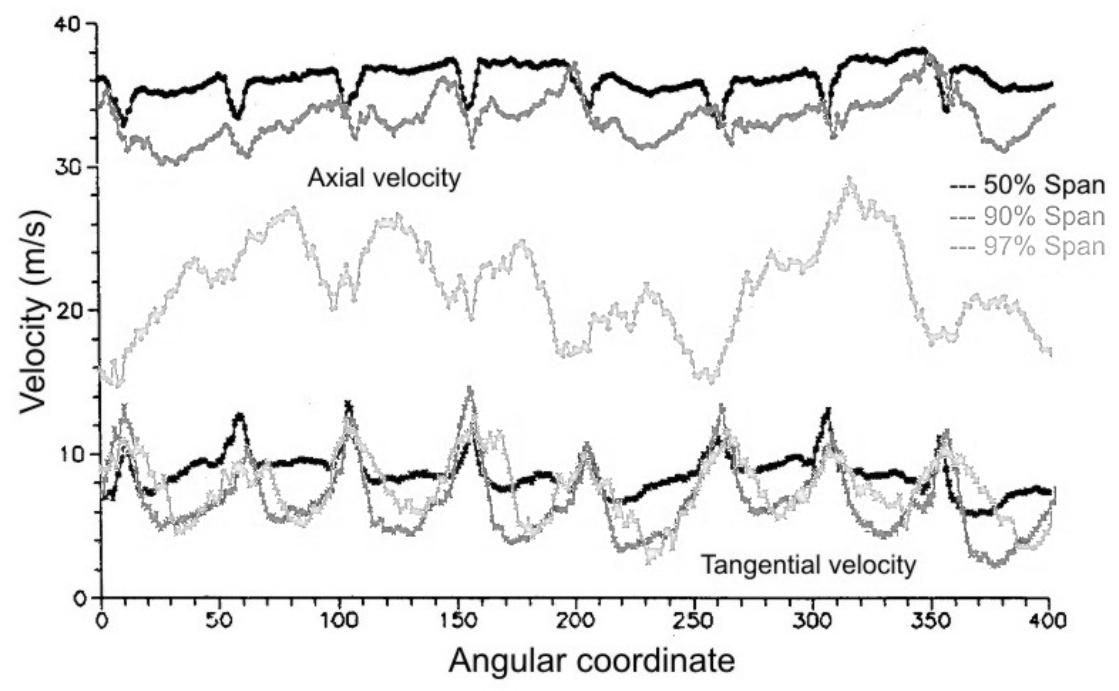

Fig. 5. Ensemble-averaged velocities at midspan and near the tip region.

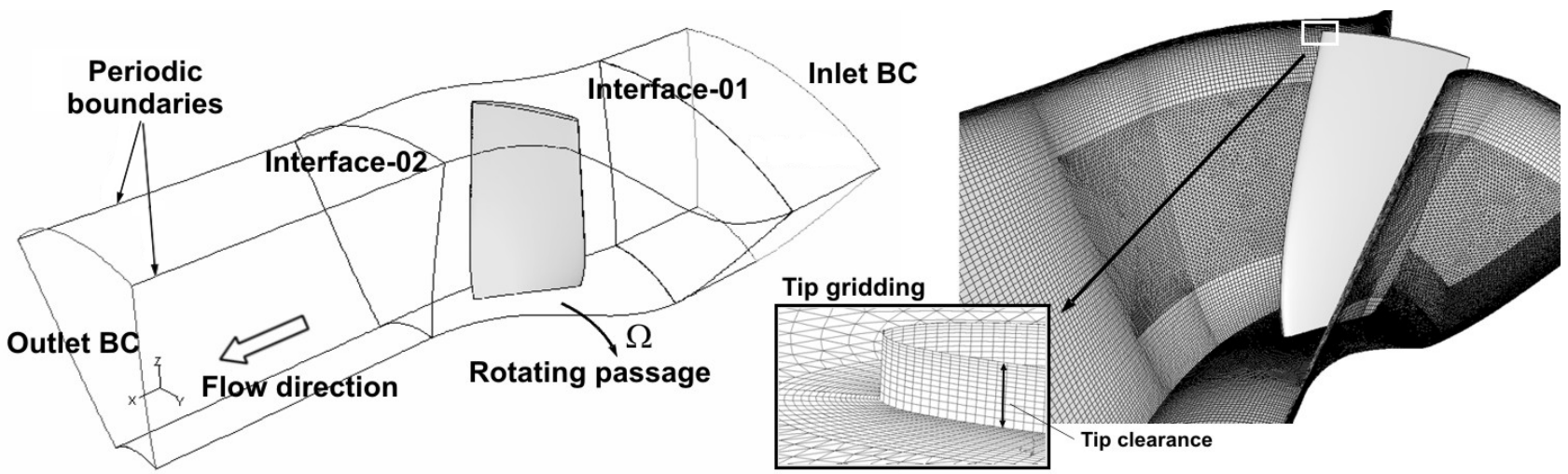

Fig. 6. Numerical blade passage. Tip clearance gridding.

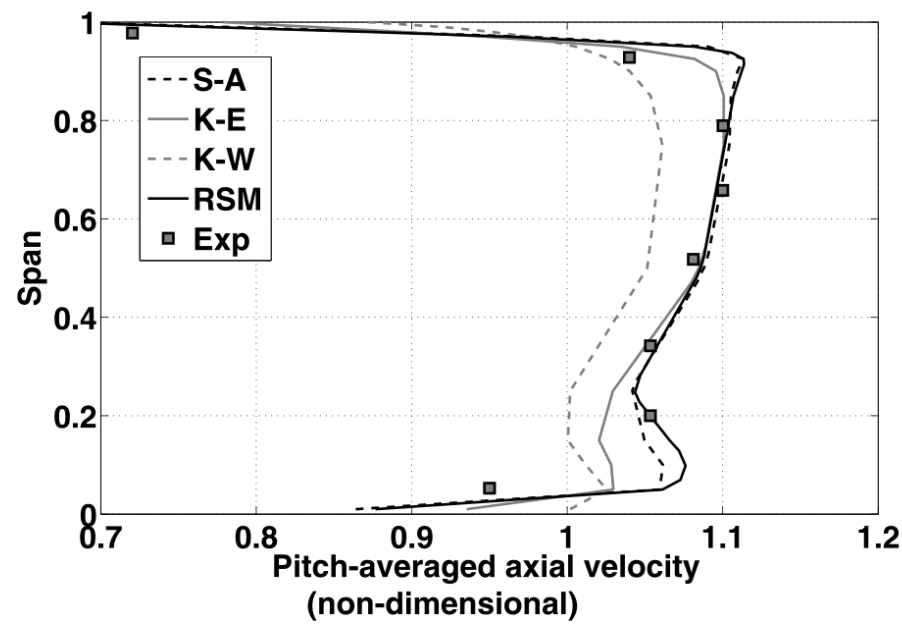

Fig. 7. Comparison of turbulence models: effect on the velocity profile. 


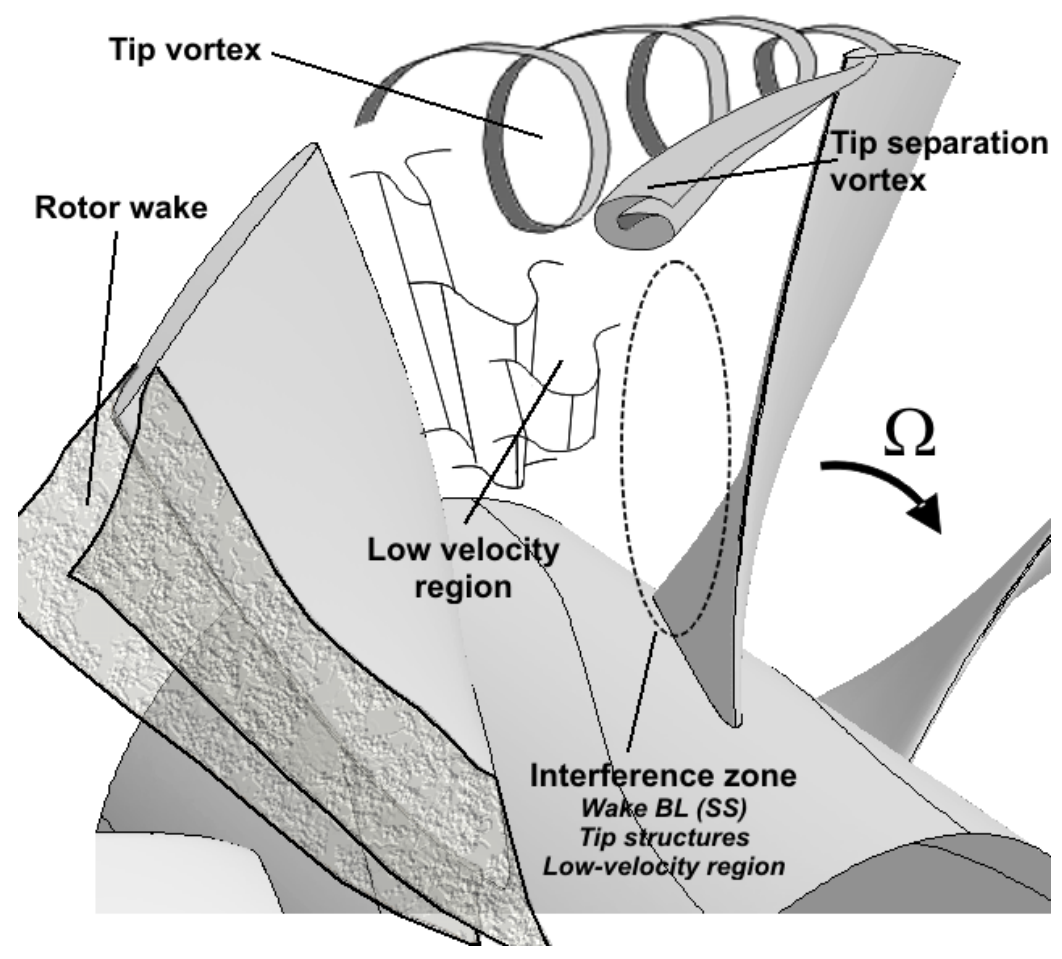

Fig. 8. Illustration of the flow structure in the rotor passage.
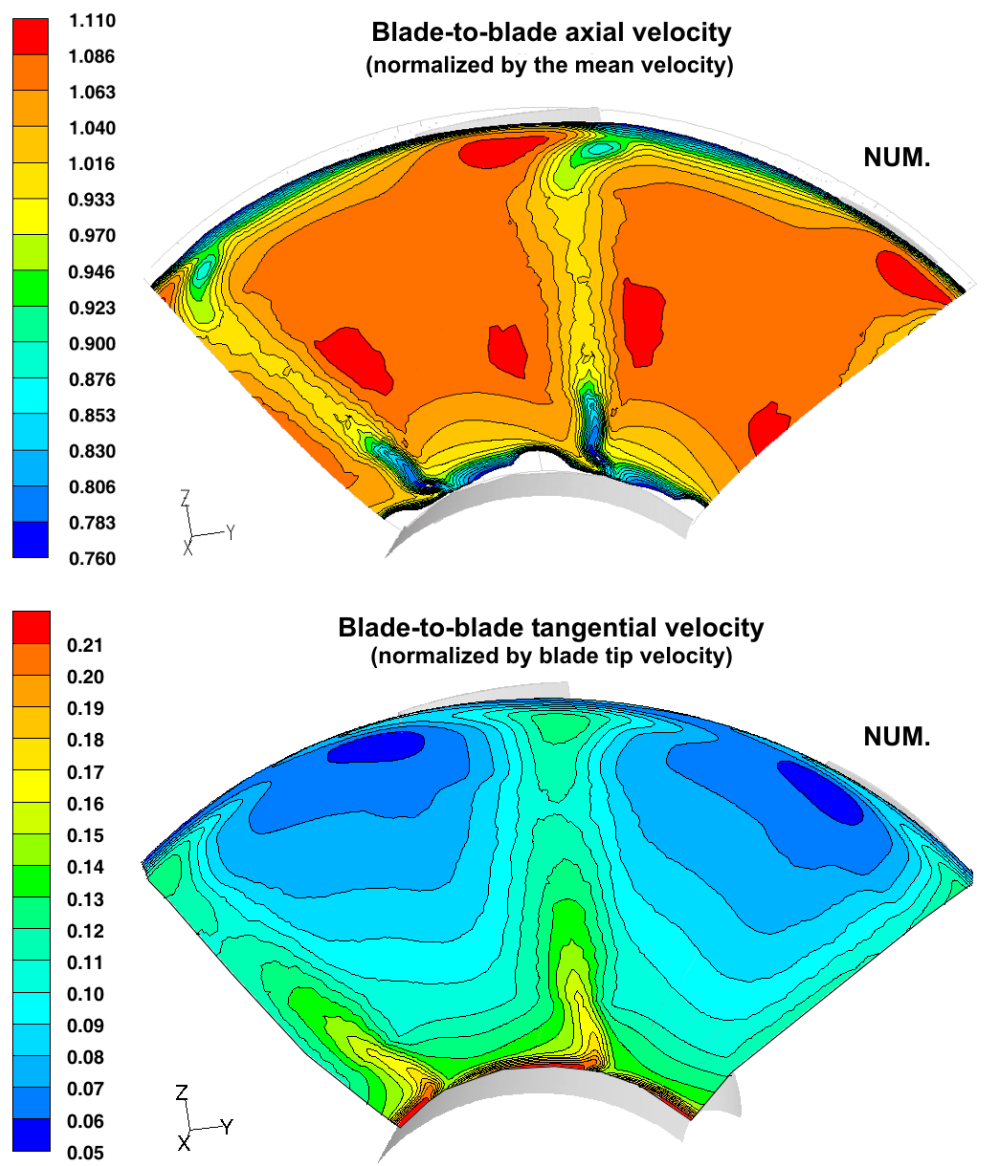

Fig. 9. Numerical velocity distributions rotor downstream. (a) Axial. (b) Tangential. 

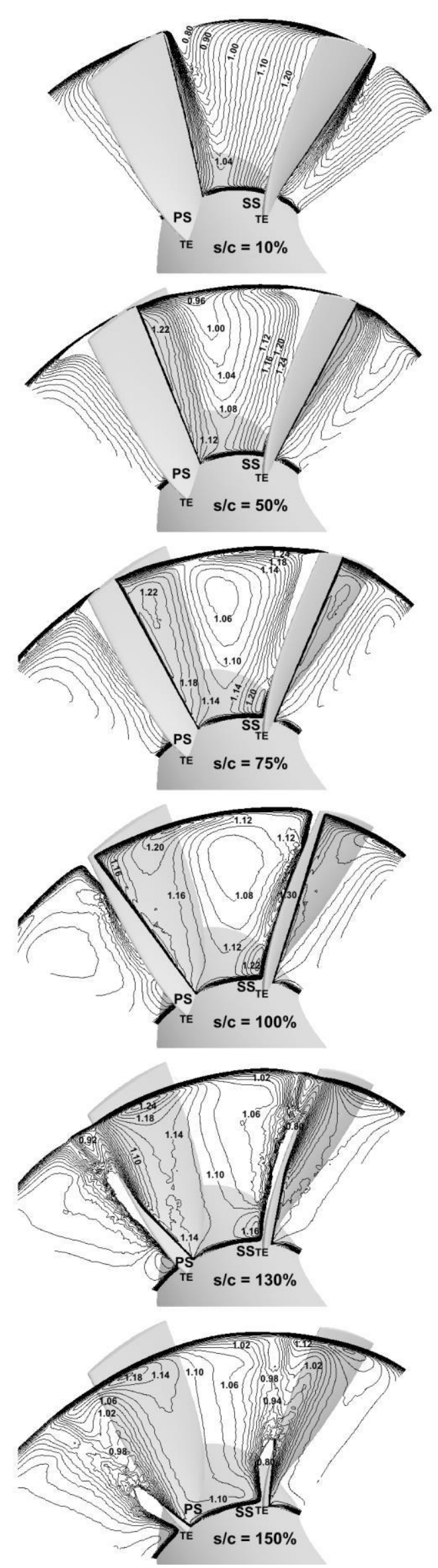

Fig. 10. Numerical distribution of axial velocity along the blade passage. 


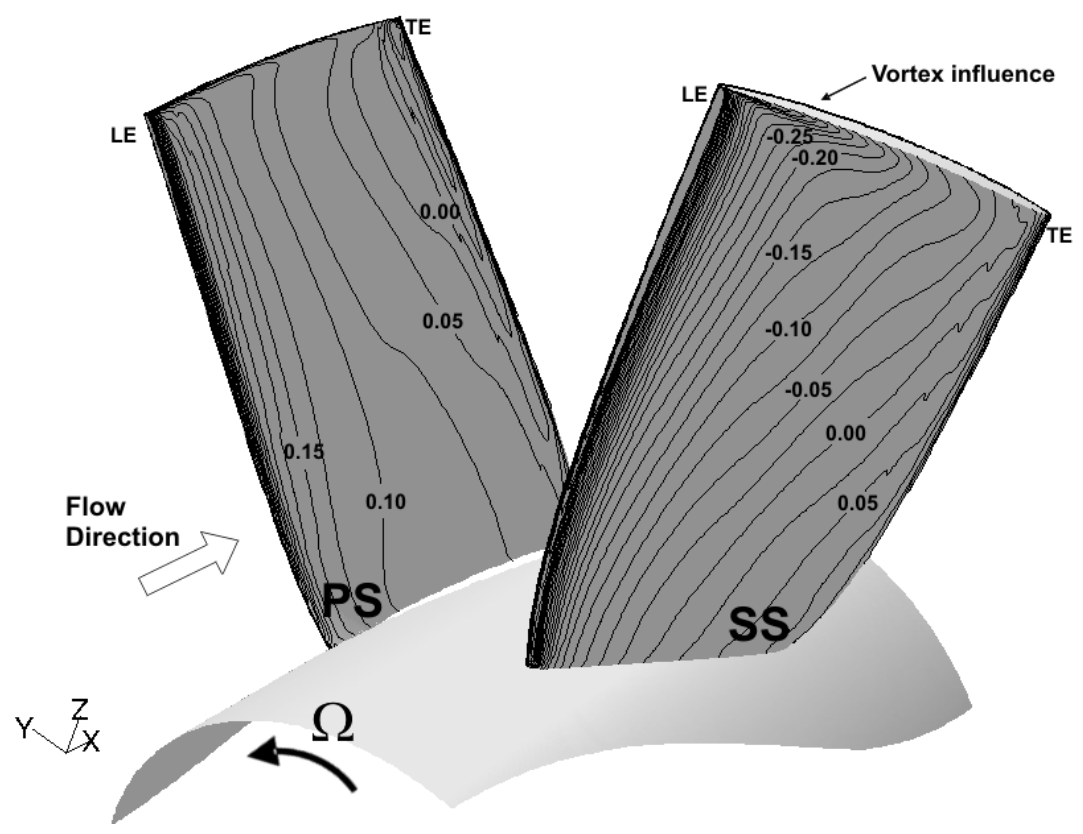

Fig. 11. Contours of $\mathrm{Cp}$ on the blade surfaces.
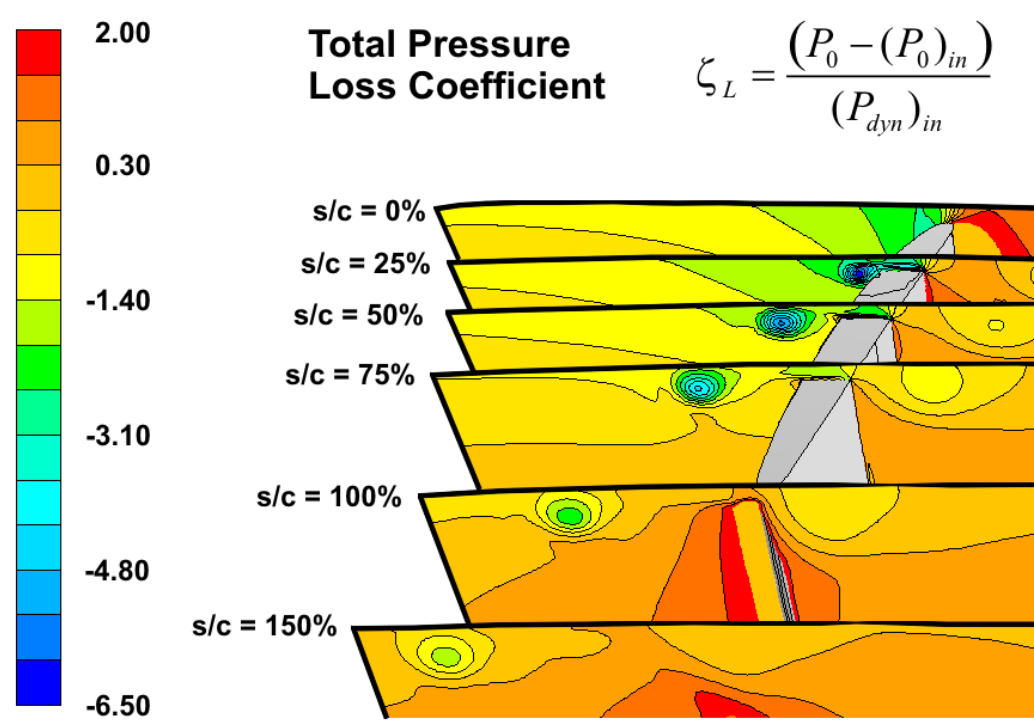

Fig. 12. Evolution of the loss coefficient in the tip region along the blade passage. 

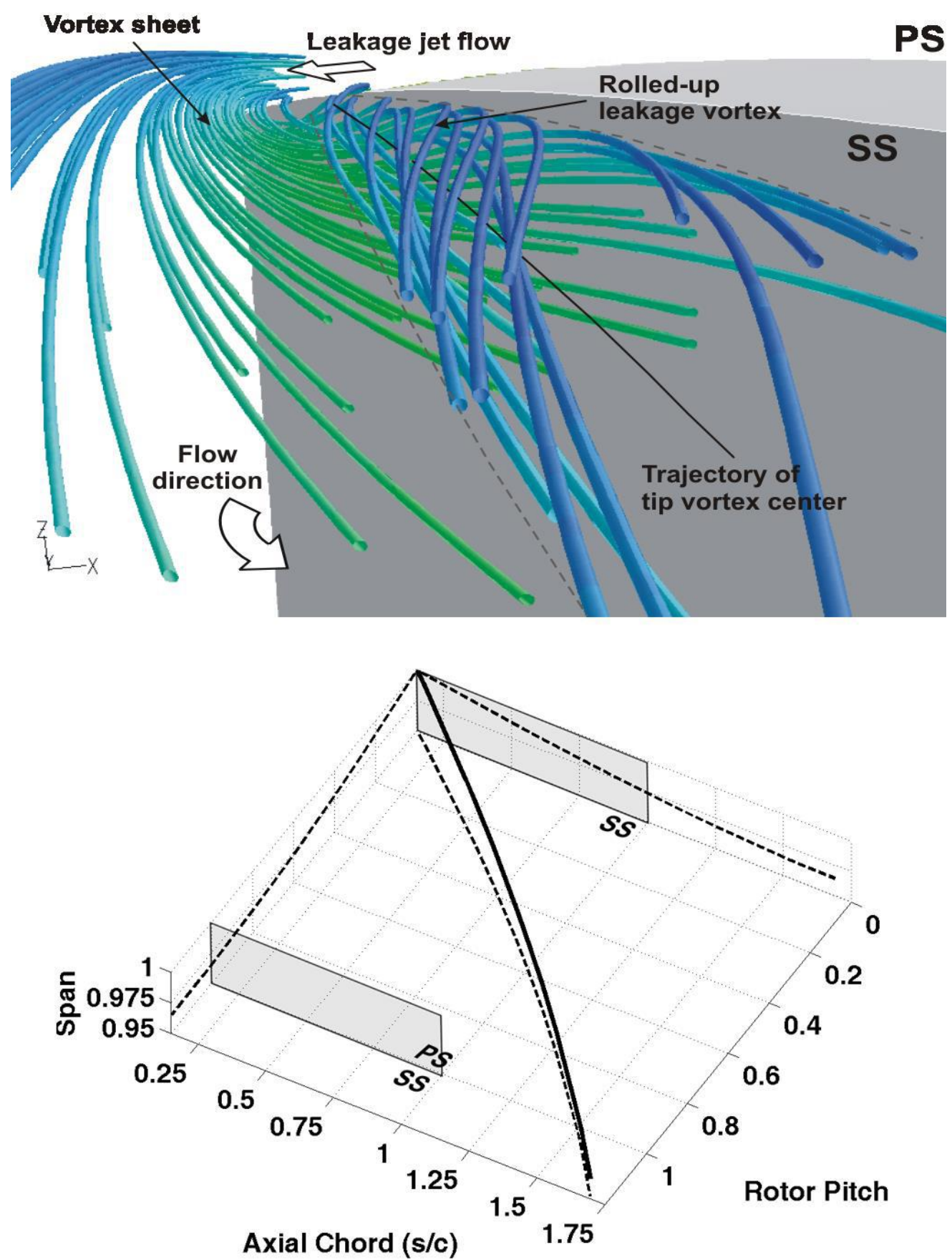

Fig. 13. Tip vortex trajectory for intrinsic coordinates. 


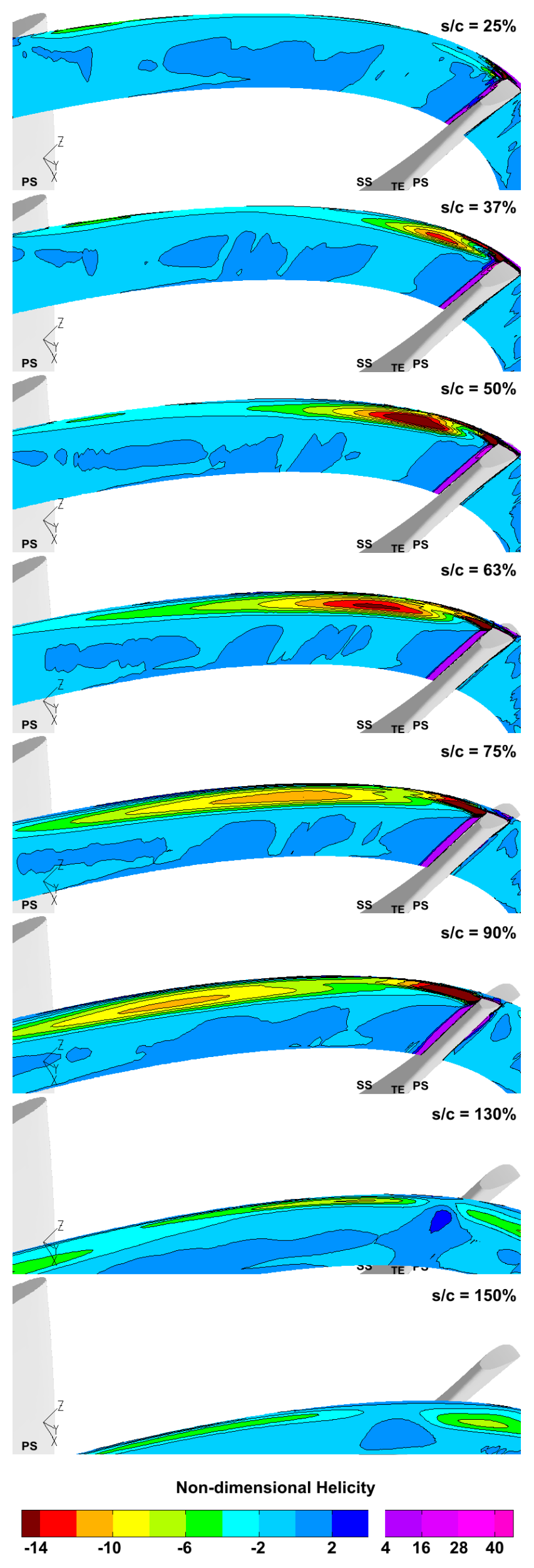


Fig. 14. Contours of helicity along the blade passage.

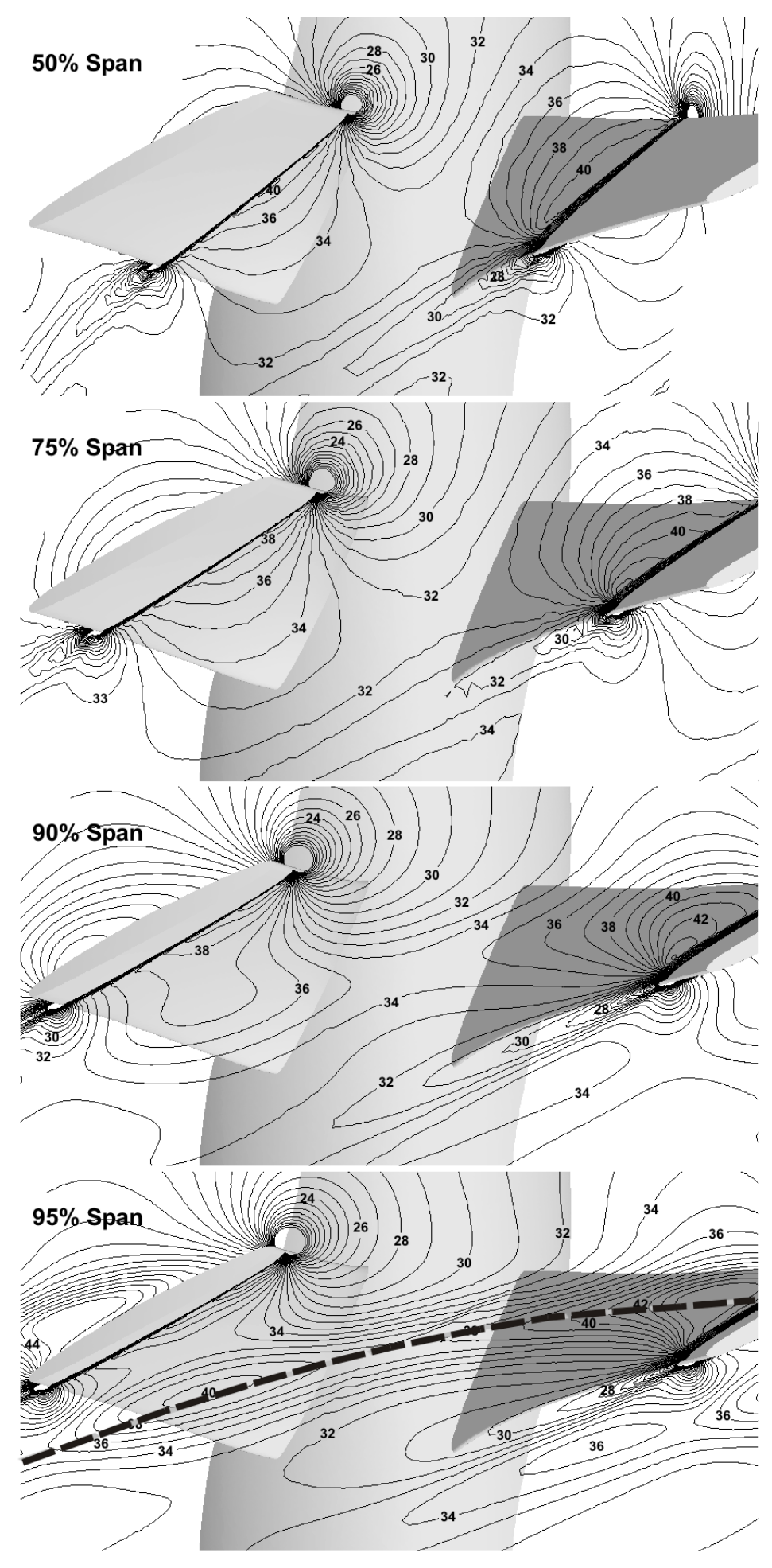

Fig. 15. Blade-to-blade distributions of axial velocity at different radial inmersion. 


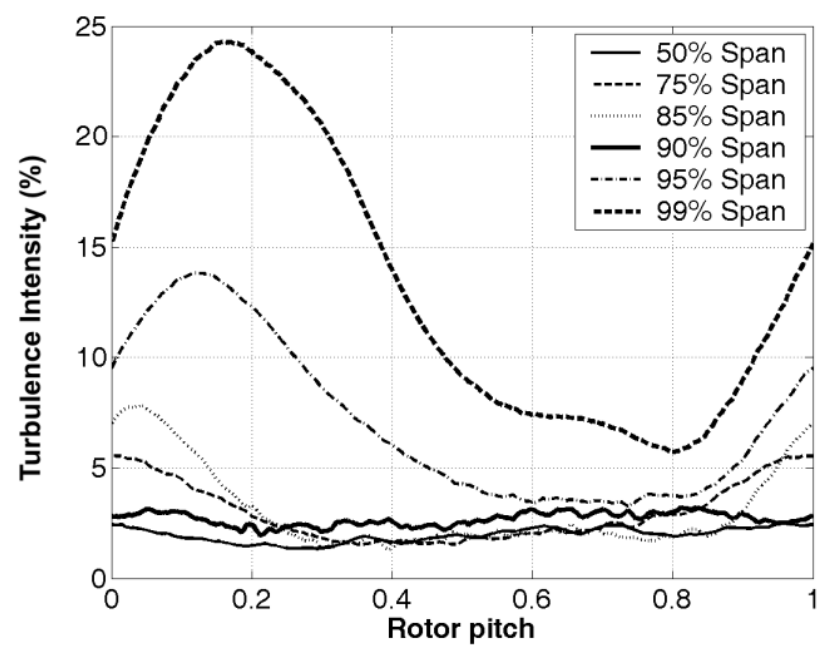

Fig. 16. Spanwise turbulence intensity.

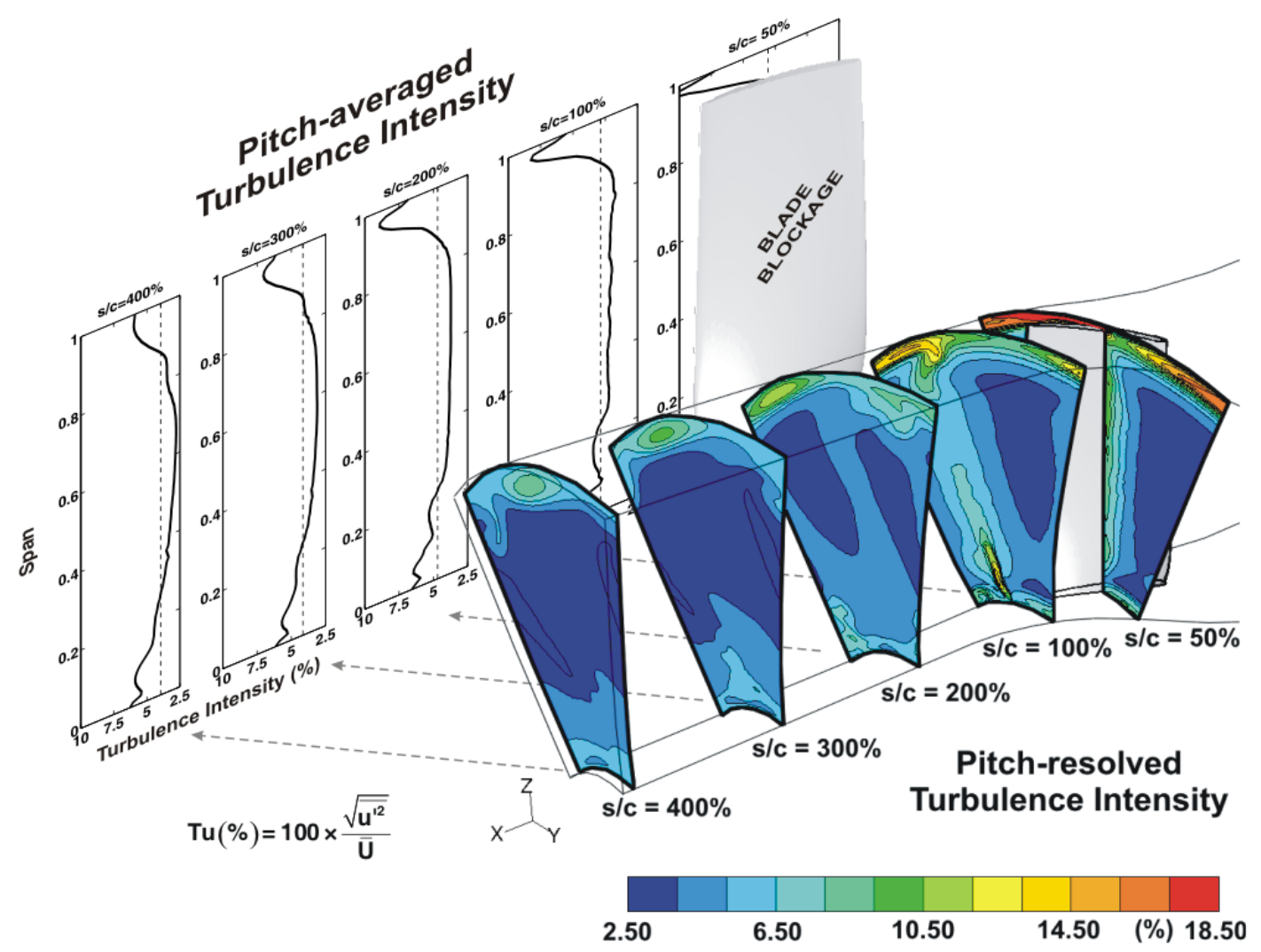

Fig. 17. Pitch-averaged turbulence intensity along the jet fan. 
This document is a pre-print version of the scientific paper published by SAGE Publishing. It has been released by the authors to fulfill all the publisher requirements established for Article Sharing:

https://uk.sagepub.com/en-gb/eur/journal-author-archiving-policies-and-re-use

\section{(c) 1 (i) (9)}

(C) 2019. This manuscript version is made available under the Creative Commons Attribution-NonCommercial-NoDerivatives 4.0 International License (CC-BY-NC-ND 4.0 license) http://creativecommons.org/licenses/by-nc-nd/4.0/ 